\title{
Four Flavours of Customers: A Dual-System Perspective on Self-Service Technology Use
}

\section{Tapani Rinta-Kahila}

Australian Institute for Business and Economics, The University of Queensland, Brisbane, Australia

t.rintakahila@uq.edu.au

\section{Esko Penttinen}

Aalto University School of Business, Helsinki, Finland

\section{Abstract}

Self-service technologies (SSTs) increasingly permeate retail spaces. To make their SST investments worthwhile, retailers need to turn enough customers into SST users. Previous research has uncovered the significance of habitual behaviour stemming from prior experience and situational factors from the environment on SST use. However, consumers are likely to vary regarding the extent they are driven by either habit or situational factors, suggesting that different types of consumers might exist in this regard. In this paper, we probe these consumer types in a real-life choice situation by studying the choice of selecting a checkout option (either staffed or self-checkout). We conduct a field study employing mixed qualitative methods by observing and interviewing customers checking out from retail stores. We discover four distinct customer types regarding the extent of reflexive (automatic) and reflective (deliberate) processing they use in their checkout selection: habitual traditional checkout users, habitual SCO users, situational users, and drifting users. We discuss the implications of our findings by linking the cognitive processing styles to the different stages of technology acceptance. Our main contribution lies in the development of a typology of consumers based on their selection between SST and human-delivered service.

Keywords: self-service technologies, consumer typology, dual-system theories, grocery industry, field study.

\section{Introduction}

New technologies are increasingly reshaping consumers' retail experience (Atapattu, Sedera, \& Ravichandran, 2014; Roy, Balaji, Sadeque, Nguyen, \& Melewar, 2017). Recent advancements in areas such as digital payment options (e.g., contactless and mobile payments) and automatic check-out channels (e.g., self-checkouts, automatic parcel stations, and even unstaffed grocery stores) are nudging consumers to change their incumbent routines (Chen, White, \& Hsieh, 2020; Gelderman, Ghijsen, \& van Diemen, 2011; Vannucci \& Pantano, 2019), ultimately putting consumer choice calculus to the test. Rolling out these technologies requires investments by retailers, which, in turn, requires adoption decisions by consumers to make these investments worthwhile for retailers (Collier, Sherrell, Babakus, \& Horky, 2014; Evanschitzky, Iyer, Pillai, Kenning, \& Schütte, 2015; Rinta-Kahila, Penttinen, Kumar, \& Janakiraman, 2021). The question of what prompts a consumer to choose technology-delivered service becomes especially apparent in settings where self-service technologies (SSTs) are offered as an alternative to traditional human-delivered service mode. As ever more sophisticated smart technologies such as robotic shopping companions (Bertacchini, Bilotta, \& Pantano, 2017) are being 
developed into physical retail settings, understanding the abovementioned dynamics is increasingly important.

Situational factors such as waiting times and time pressure have been found to significantly influence SST use intentions and behaviour (Chen, Yu, Yang, \& Wei, 2018; Collier, Moore, Horky, \& Moore, 2015; Penttinen, Rinta-Kahila, Ronkko, \& Saarinen, 2014; Wang, Harris, \& Patterson, 2012). Then again, incumbent habits have been established as powerful drivers of SST use too (Wang, Harris, \& Patterson, 2013, 2017). However, little is known about how situational factors and habits interact and whether their effects are different for different types of consumers. Blut et al. (2016) note that the various predictors of SST use should be examined jointly to gain a comprehensive understanding of user behaviour. This invites us to explore the extent to which the interplay of situational factors and habit shapes consumers' choice behaviour and to consider that different types of consumers might be affected in different ways.

Previous research has established that consumers can be classified into different types with regard, for instance, the temporality of technology adoption (e.g., innovators and laggards in Rogers (2003)), the extent of technology use (e.g., intense vs. specialized in Shih \& Venkatesh (2004)), ways of using social media (e.g., sporadics vs. actives in Brandtzæg \& Heim (2011)), and level of experientiality in consumption (e.g., hedonic, holistic, and utilitarian consumers in Zarantonello \& Schmitt (2010)). Distinguishing between different types helps service providers to create circumstances that nurture the consumption or technology adoption of each user group. However, it is not clear whether distinct behavioural types exist with regard to consumer's choice between technology and human-delivered service. This leads us to ask: 1. Can different types of consumers be distinguished based on their choice between SST and human-delivered service? and 2. If yes, how do these types differ in their decision-making regarding SST use? We investigate the questions in the grocery retailing context (Kurnia, Belts, \& Johnston, 2002), where customers operate in a highly dynamic environment that burgeons with external cues and triggers.

Existing work has probed the topic of SST adoption and use mainly by inquiring consumers' abstract perceptions of the technology of interest (Lien, Hsu, Shang, \& Wang, 2019), and studies that account for situational factors tend to survey consumers about imaginary or hypothetical situations (Collier et al., 2015; Simon \& Usunier, 2007). Yet, we do not often even realise the effect of external and environmental stimuli on our behaviour (Ortiz de Guinea \& Markus, 2009), and retail settings tend to be dynamic and even chaotic at times. Therefore, surveys that measure consumers' technology perceptions need to be complemented with approaches that probe how experienced environmental stimuli shapes consumer behaviour.

To investigate our questions, we draw on prior literature's conceptualization of two interconnected cognitive systems that feed stimulus to consumer choice behaviour: a reflexive automatic mode and a reflective controlled one. Such frameworks, generally known as dualsystem theories, have significant potential to deepen our understanding of consumer decision making (Bond, Bettman, \& Luce, 2009; Dhar \& Gorlin, 2013; Gawronski, 2013; Gorlin \& Dhar, 2013). We thus began by using purposive sampling (Polkinghorne, 2005) to select a clear consumer choice situation where both reflexive and reflective modes are imaginable, and where a researcher may observe the actions taken by the consumer and make further inquiries immediately after the choice. As a result, we chose to focus on consumers selecting either a traditional staffed cashier or an unstaffed self-checkout (SCO) in grocery stores. 
We conducted an empirical field study by observing and interviewing customers frequenting three grocery stores that all offer both traditional service and an SCO option. By probing customers' cognitive processing in the choice situation via the above-mentioned methods, we found that four types of consumer behaviour can be distinguished: habitual SCO users, habitual traditional checkout users, situational users, and drifting users.

This paper is organised as follows: Section 2 sets the scene by articulating our current understanding regarding the selection of SCOs over traditional checkouts. Section 3 establishes the theoretical background of this study by discussing dual-system theories. Section 4 describes the empirical study in terms of data collection and data analysis. Sections 5 and 6 are dedicated to the findings and their implications, respectively.

\section{Setting the scene: the selection of self-checkout over traditional checkout}

Self-service technologies (SSTs) such as self-checkouts (SCOs) empower consumers by providing them with increasing choice freedom (Broniarczyk \& Griffin, 2014). By implementing SCOs, retailers hope to achieve increased sales through providing more attractive service environments, as well as to reap cost savings through more effective management of staff and customer waiting times (Weijters, Rangarajan, Falk, \& Schillewaert, 2007).

Previous research on SST adoption and use indicates that customers' perceptions of SST (Amorim, Lago, Moscoso, \& Prieto, 2016; Beatson, Lee, \& Coote, 2007; Blut, Wang, \& Schoefer, 2016; Galletta, Durcikova, Everard, \& Jones, 2005; Lien et al., 2019) play a major role in explaining SST use behaviour. Relevant perceptions typically relate to SST's usefulness, convenience, and ease of use, among other factors. These perceptions, in turn, are shaped by individual demographic factors like age and gender (Dean, 2008; Venkatesh \& Morris, 2000), as well as psychographic characteristics like inherent thinking styles (Simon \& Usunier, 2007), technology anxiety (Chen et al., 2020), and personal values (Lee \& Lyu, 2016). However, the high dynamism of the retail checkout environment makes the decision to use or not to use SST a highly contextual and situational phenomenon. This suggests that inherent thinking styles or abstract perceptions of technology may not sufficiently explain the choice between traditional service and SST. Accordingly, situational factors like perceived or experienced waiting time (Djelassi, Diallo, \& Zielke, 2018; Gelderman et al., 2011) and automatic behaviours like habits (Wang et al., 2013, 2017) have been found to significantly shape SST use behaviour. Wang et al. (2013) find that customer's decision to continue SCO usage is initially rationally driven, then emotionally driven, and finally becomes habitual. This suggests that attitude and intention alone do not always predict actual behaviour exhaustively. Even though the link is strong in the initial usage phase, the significance of deliberate attitudes and intentions weakens during the habit formation and thus they are inadequate to explain automatic, habit-driven behaviour (Limayem, Hirt, \& Cheung, 2007; Wang et al., 2013, 2017). However, for a habit to form, customers need to adopt and use the technology first. Previous research on SST use has found that customers encounter significant trade-offs when it comes to embracing SSTs (Parasuraman, 2000; Vannucci \& Pantano, 2019). These are often related to customers' predispositions and discomfort toward new technologies, and they materialise, for instance, as the complexity of learning to use SST and the fear of failure when operating it (Liao \& Cheng, 2013; Liljander, Gillberg, Gummerus, \& van Riel, 2006; Parasuraman \& Colby, 
2015; Zhu, Nakata, Sivakumar, \& Grewal, 2013). Thus, it is no wonder that the incumbent habit of using traditional human service can be strong, and not every customer is willing to become an SST user (Gelderman et al., 2011).

Although previous research has established that both habit (Venkatesh, Thong, \& Xu, 2012; Wang et al., 2013) and situational factors (Collier et al., 2015; Wang et al., 2012) shape SST use behaviour, it has not gone deeper into examining the universality of these effects. While evidence of their overall significance exists, there are good reasons to believe the effects are different for different types of consumers: some might be more resistant to situational triggers and stick to their behavioural patterns while others may operate more dynamically. This raises the question about what different types of consumers exist with regard to the choice between SST and human-delivered service. We posit that drawing on dual-system theories can shed new light on the SST use (or non-use) phenomenon by helping to uncover how environmental cues and internal habits translate into behavioural outcomes through one's cognitive processing.

\section{Theoretical review}

This section lays the theoretical foundations for the current study by discussing dual-system theories and how they link to habits.

\subsection{Dual-system theories}

Dual-system theories posit that humans' thought processes are best represented by two discrete yet interactive systems, which we refer here to as the reflexive system (one that processes data automatically) and the reflective system (one that processes data deliberately) (Dhar \& Gorlin, 2013; Kahneman, 2003, 2011; Laureiro-Martínez \& Brusoni, 2018; Lieberman, 2007). These systems are not isolated but are interconnected and parallel in complex ways (Gawronski, 2013; Martin \& Sloman, 2013). This may manifest sequentially in a way that the reflexive system feeds material to the reflective system which then corrects or filters the effects of the reflexive impulses before they materialise in actual behaviour (Bond et al., 2009).

One important distinction between dual-system theories concerns their primary focus (Bond et al., 2009) which can relate either to a) broader theory of personality, emphasizing individual characteristics (e.g., Epstein, 1994) or b) situational behaviour, highlighting the reasoning regarding a specific task (e.g., Kahneman, 2003; Sloman, 1996). Thus, researchers may choose to concentrate on the characteristic processing styles tied to the decision-maker's personality or alternatively to focus on the thought processes immediately related to the task or choice behaviour itself. One example of the former type of theory is Epstein's (1994) cognitiveexperiential self-theory (CEST), which suggests that people differ in the degree to which they characteristically operate in rational or experiential style. The dominance between these two systems has also situational variations, namely situational circumstances and emotional arousal which can be considered as moderating factors (Epstein, Pacini, Denes-Raj, \& Heier, 1996). Simon and Usunier (2007) apply CEST to study the influence of personal thinking styles on the choice between SST and traditional human-delivered service and find that in the case of complex services, high rational engagement and low experiential style contribute to SST preference. Vice versa, low rational engagement and high experiential style promote preference for personal service. However, the influence of the personal thinking style was found non-significant if the service is perceived as simple, and the situational effect of waiting time was smaller than with complex technologies. On the other hand, Kahneman's (2003) 
division between System 1 and System 2 (Stanovich \& West, 2000) concerns the immediate task-specific processes and thus needs to be investigated in a real-life setting. Finally, some consumer studies leverage the dual-system perspective to investigate self-control dilemmas, such as excessive use of the internet and social media ( $\mathrm{Li}, \mathrm{Guo}, \& \mathrm{Yu}, 2019$; Osatuyi \& Turel, 2018; Turel \& Qahri-Saremi, 2016). In such studies, the different levels of focus are sometimes mixed (Bond et al., 2009), e.g., Soror et al. (2015) examine how a specific personal trait (general self-regulation) interacts with a behaviour bound to a certain context (habit of mobile phone use).

\subsection{Habits}

One focal aspect of information processing relates to habits, which can be defined as learned sequences of actions that are automatic responses to specific situations and function in attaining certain goals or end states (Verplanken, Aarts, \& VanKnippenberg, 1997). While habitual behaviour tends to occur without active awareness, habits are intentional in the sense that they have a functional or goal-oriented motivation or origin (Polites \& Karahanna, 2012). Thus, the formation of habit requires conscious reflection before it becomes automatic. This makes self-efficacy an important antecedent of habit in the early stages of technology use when one is learning a new behaviour (Wang et al., 2013, 2017). From the dual-system perspective, this means that one's processing style of a certain behaviour may change over time and through repetition: reflective processing required for learning to perform the behaviour changes into reflexive processing through habit formation (Aarts \& Dijksterhuis, 2000). Habit is then triggered by specific situational cues, often outside the awareness of an individual. Habits are mentally efficient, meaning that they free an individual's cognitive resources for other tasks (Polites \& Karahanna, 2012). Partly due to this, habits are often difficult to control or suppress (Aarts \& Dijksterhuis, 2000; Soror et al., 2015). Overall, habit formation is associated with developing expectations about behaviour, which further reduces both the individual's sensitivity to variations in the environment (e.g., situational factors) and one's reflection and deliberation of the behaviour (Verplanken and Wood, 2006, p. 91). Moreover, automatic and reflexive (and thus sometimes even unconscious and involuntary) behaviour may originate from a reasoned choice based on highly analytical reflection.

\subsection{Conceptual framework}

Based on the discussion of habits' powerful influence on behaviour, we expect some consumers to be driven with their prior experiences and thus stick to their incumbent habits regardless of other service options that might be available. Yet, it is likely that not all consumers make the choice automatically. Shopping tends to occur in a somewhat chaotic environment where, besides their objectives and preferences (e.g., habits, internal requests), shoppers are subjected to the influence of various environmental forces (e.g., crowdedness, store staff availability, external requests) (Gelderman et al., 2011; Wang et al., 2012). This means that some might apply deliberate reflection to optimize their choices. Interestingly, in a recent meta-analysis, Blut et al. (2016) find insufficient support for habit determining actual SST use behaviour. This finding contradicts some previous research on the topic (Venkatesh et al., 2012; Wang et al., 2013) but points to the possibility that some consumers might make more situational choices than they think they do. Considering that habits can be unconscious, extant theories on technology use behaviour and conventional survey methodology may be insufficient for capturing the existence of habit. Then again, it could be that situational triggers can sometimes overcome habit (at least with some consumers), weakening its aggregate effect 
on behaviour. These possibilities and the general lack of considering cognitive processing in the choice between SST and human-delivered service invite us to take a dual-system approach on the topic in a real-life field study setting. Figure 1 illustrates how habits stemming from prior experience and situational factors in the choice environment exert their competing influences on consumer's cognitive processing. The tug of war between reflexive and reflective processing then results in alternative outcomes. Our research investigates what kinds of behavioural types can be distinguished based on the interplay between these two sources of influences.

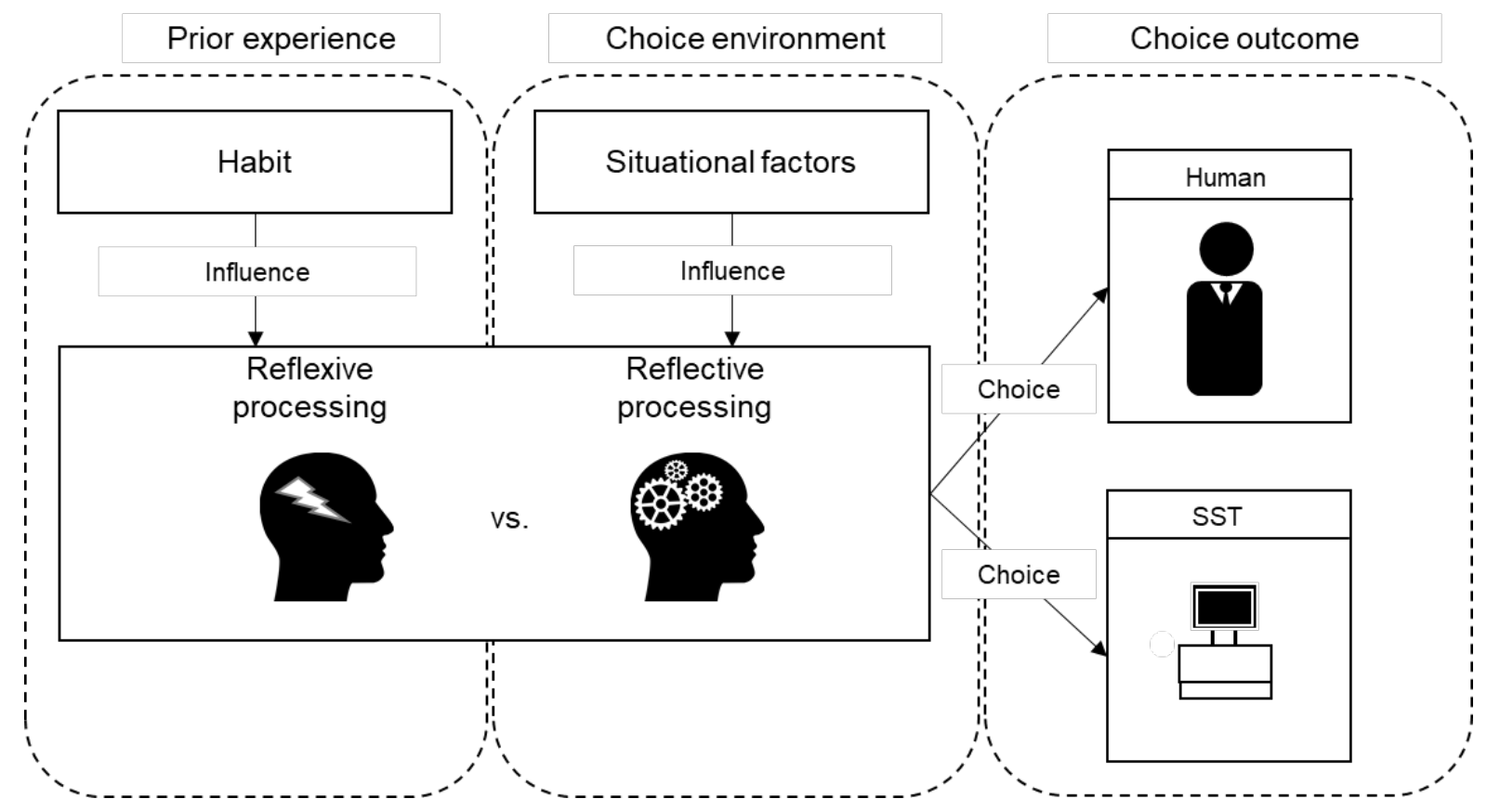

Figure 1. Conceptual framework

\subsection{Research approach}

To produce a typology of consumer behaviours based on SST-related decision-making behaviour one needs to capture the extent to which situational triggers cause consumers to switch their cognitive gears from automatic mode to deliberate thinking and vice versa (Louis \& Sutton, 1991). To this end, the discussion above points to the importance of capturing a) the level of cognitive processing one used in a choice situation, $b$ ) the environmental cues one experienced, and c) one's incumbent habits and attitudes. The challenge of directly measuring one's level of cognitive processing and the difficulty to accurately perceive or recall environmental cues suggests that these should be probed as soon as possible after the decisionmaking situation. The fact that consumers' cognitive processing often happens without their active awareness indicates that one could approach measuring the extent of reflection by applying indirect proxy questions, such as the extent to which they deliberately surveyed the crowdedness of the SST use area. The level of processing, in turn, helps to establish the extent of habitual behaviour (i.e., low level of processing indicates strong habit), which can be further ascertained by inquiring about consumers' prior experiences, behavioural patterns, and general experiences with the SST.

Thus, drawing on the interplay of reflexive and reflective behaviour that is subject to both habit and situational cues, and building on the past work conducted in similar settings (Simon 
\& Usunier, 2007), this paper explores how consumers differ in making the choice between SST and human-delivered service.

\section{Empirical study}

Surprisingly, especially given the vast body of literature on the various forms of dual-system theories, there exist very few studies in which researchers would have attempted to empirically tap onto the reflexive and reflective processing modes in consumer-choice situations. Attempts in the extant literature to distinguish between the two processing modes can be categorised roughly into three approaches. First, it is known that when an individual engages in reflective processing, her pupils tend to dilate, heart rate increase, and level of blood glucose drop (Kahneman, 2011). Also, it has been shown that different patterns of neural activation in brain activity can be spotted supporting reflective or reflexive social cognition (Lieberman, 2007). However, detecting these types of psycho-physiological changes in reallife consumer choice settings such as in retailing would be cumbersome. Second, the difference in response time has become the most commonly accepted measure to distinguish between reflective and reflexive cognitive modes; reflexive processing being fast, reflective slow (Laureiro-Martínez \& Brusoni, 2018). Relying on response latencies, the IAT (Implicit Association Test) is a popular method for determining implicit cognition. While such methods might perform well in laboratory settings, we posit that they pose insurmountable measurement challenges in real-life consumer choice settings. Third, survey-based research conducted in imaginary (Meyers-Levy \& Maheswaran, 2004; Simon \& Usunier, 2007) or recalled (Soror et al., 2015; Turel \& Qahri-Saremi, 2016) decision situations has severe limitations in capturing actual choice behaviour and cognitive processes behind it.

Earlier research on customer choice between SST and human-delivered service suggests that the emphasis should be on actual behaviour rather than on attitude and behavioural intentions (Meuter, Bitner, Ostrom, \& Brown, 2005). Thus, a field study was conducted in grocery stores that offer both SCOs and traditional checkout options for their customers. Taking an interpretive approach has been found useful when investigating novel phenomena in the SST context (see, Bitner, Booms, \& Tetreault, 1990; Meuter, Ostrom, Roundtree, \& Bitner, 2000; Wang et al., 2012). While the SST research is reaching saturation, this study takes a previously uncharted perspective on SST usage by considering the cognitive processes that take place in a real-life decision-making situation. Especially in a case like this where no previously established methodology exists for investigating the research question, it can be argued that an interpretive approach is appropriate in the initial exploration of the phenomenon, which could then pave the way for more systematic inquiries. As such, a structured interview protocol was designed to tap on the cognitive processes of customers right after performing the behaviour of interest, namely checking out from a grocery store. In line with Wang et al. (2012), this study leverages the benefits of both objective observational data and interpretive interview data.

\subsection{Data collection}

The data collection methods included both non-participant observations and structured interviews at the service sites. These methods were chosen because while interviewing allows one to capture customers' subjective experience of the checkout selection, observation provides the researcher with relevant situational information regarding the event. To get permission for data collection, one of the largest grocery-retail chains in Finland was 
approached for cooperation. The chain gave their approval for the data collection in three of their grocery stores that had implemented SCOs, referred to as Site A, Site B, and Site C. The stores are virtually identical in terms of size and product assortment, and they are all situated in busy, central locations in the capital. Moreover, the chain also provided us chocolate bars to be given for each informant as an incentive and reward for participating in the interview. Before the field study, the authors interviewed the store managers of Site A and Site B to gain an overall understanding of the objectives of the SCO implementation and its effect on the daily operations in the stores.

The data was collected by one of the authors and a research assistant. During the field study, the two data collection methods were applied sequentially, starting by observing the customer and continuing with an interview. Specifically, the observation started when a customer entered the checkout area and ended after the transaction was finished and the customer was invited for an interview. The selection of informants was done randomly, however, the aim was to obtain roughly similar sized samples of informants from customers checking out through SCOs and the ones choosing traditional tills. If the observed customer did not want to be interviewed, that was counted as a non-response event in the overall sample. The observed items were gender, shopping tool, number of shopping companions, approximate waiting time, payment method, the number of purchases, and most importantly, the chosen checkout. Also, the subject's age was estimated, which was later confirmed in the interview if the informant was willing to share that information. Additionally, an illustration of the checkout area (see Appendix A, Table A1) was produced beforehand and filled according to the customer's movement, i.e., from which aisle the customer enters the area and which checkout is finally selected.

Observations were complemented with one-on-one interviews which were conducted immediately after the checkout. The interview form was informed by dual-system frameworks (Kahneman, 2003, 2011; Louis \& Sutton, 1991) aimed to probe situational cognitive processing, research on SST use (e.g., Wang et al., 2012), and relevant contextual considerations. Both close-ended questions with given answers to choose from and open-ended ones allowing respondents to elaborate their answers were used. Additionally, some close-ended questions had a follow-up inquiry 'why' to gain a more profound understanding of the reasoning behind the answer.

To assess the questionnaire's validity, a pilot test was conducted at Site A. In total, 17 customers agreed to take part in the pilot study. This sample consisted of ten self-checkout users and seven traditional-checkout users. After reflecting on the conducted interviews and examining the gathered data, the questionnaire was revised into its final form. Questions were reordered, wordings were revised, and more options were included in the close-ended questions. The questionnaire leveraged multiple questions to capture the extent to which customers had consciously processed situational factors, including: Did you observe the checkout area (e.g., waiting lines, other customers' purchases, free checkouts)? and Give an estimation of the extent of your observation between a range of 1-7, where 1 is minimal observation or none, and 7 is very attentive observation. Such questions also informed about the automaticity of the behaviour by indicating the extent to which habit was dominating decision-making. Also, questions about customers' previous SCO use experience were included to establish the existence of previously learned habits. Additional questions charted 
the motivations for choosing the selected checkout and whether the choice was perfunctory, among several other factors.

The final data collection stage was conducted using the revised questionnaire (see Appendix A) at Sites A, B, and C. This resulted in a sample of 69 customer observations and interviews, of which 39 checked out using SCO and 30 used traditional service. Descriptive statistics are provided in Table 1. The average age of the respondents is 38 years, ranging between 13-85 years with a standard deviation of 17.4 years. Females constitute $65 \%$ of the sample. As expected, SCO users are younger on average than those using traditional checkouts. Interestingly, SCO users bought more items on average than did traditional checkout users. Less surprisingly, customers queuing to the traditional service had to wait significantly longer time than SCO users. Most of the respondents (84\%) had tried SCOs before, and most reported intending to use them in the future. However, the ones that used traditional checkouts at the time of the interview reported remarkably lower intentions to do so.

\begin{tabular}{|l|c|c|c|}
\hline & $\begin{array}{c}\text { Traditional } \\
\text { checkout }\end{array}$ & SCO & Total \\
\hline$n$ & 30 & 39 & 69 \\
\hline Average age (years) & 43.8 & 33.1 & 37.8 \\
\hline Gender (female) & $70 \%$ & $62 \%$ & $65 \%$ \\
\hline Number of shopping companions & 0.5 & 0.3 & 0.4 \\
\hline Number of purchases & 5.4 & 6.3 & 5.9 \\
\hline Queuing time (min:sec) & $1: 44$ & $0: 08$ & $0: 50$ \\
\hline Made observations at the checkout area & $83 \%$ & $69 \%$ & $75 \%$ \\
\hline Level of observation (1-7) & 5.1 & 4.6 & 4.8 \\
\hline Checkout choice was perfunctory & $87 \%$ & $82 \%$ & $84 \%$ \\
\hline Satisfaction with the choice (4-10) & 9.2 & 9.5 & 9.4 \\
\hline Has tried SCO before / uses SCO often & $67 \%$ & $97 \%$ & $84 \%$ \\
\hline & Yes 57\% & Yes 97\% & Yes 80\% \\
\hline Intention to use SCO in the future & Possibly 27\% & Possibly 3\% & Possibly $13 \%$ \\
& No 17\% & & No 7\% \\
\hline
\end{tabular}

Table 1. Description of the sample

\subsection{Data analysis}

Customers in the sample divide naturally into two groups: the ones who checked out using traditional checkout and the ones who checked out using SCO. The objective was to distinguish between habitual and situational behaviour by tapping on to the types of cognitive processing they applied in their checkout channel selection. We conducted data analysis in three distinct steps.

First, we extracted the content of the interview forms and our additional notes by manually tabulating the data into a conceptual matrix in Excel. The data was structured per different factors that were probed in the observation and interview stages. The individual research subjects (i.e., consumers) were listed on vertical rows and the variables captured in the data collection stage were recorded horizontally into the table's columns. This allowed us to take a holistic view of the sample and start producing classifications. Any data that could not be fitted to the readily structured columns (e.g., additional notes, customer's comments) was recorded into a column for extra information that could be used to inform classifications. 
Second, we produced an initial classification of consumers by looking into the automaticity of their choice by translating the data into a tree-like structure. This tree had a root value (total sample) and subtrees of children with parent nodes depending on the data values. We first divided the sample into those who checked out using traditional checkout and those who used SCO. We expected to find consumers whose checkout channel selection was automatic (i.e., reflexive) and those whose selection was deliberate (i.e., reflective). To this end, we leveraged three main metrics: consumer's prior SCO use experience, intentions to use SCO, and the extent of observing the checkout area before checking out. Figure 2 illustrates the tree-like structure of the data and the analytical approach.

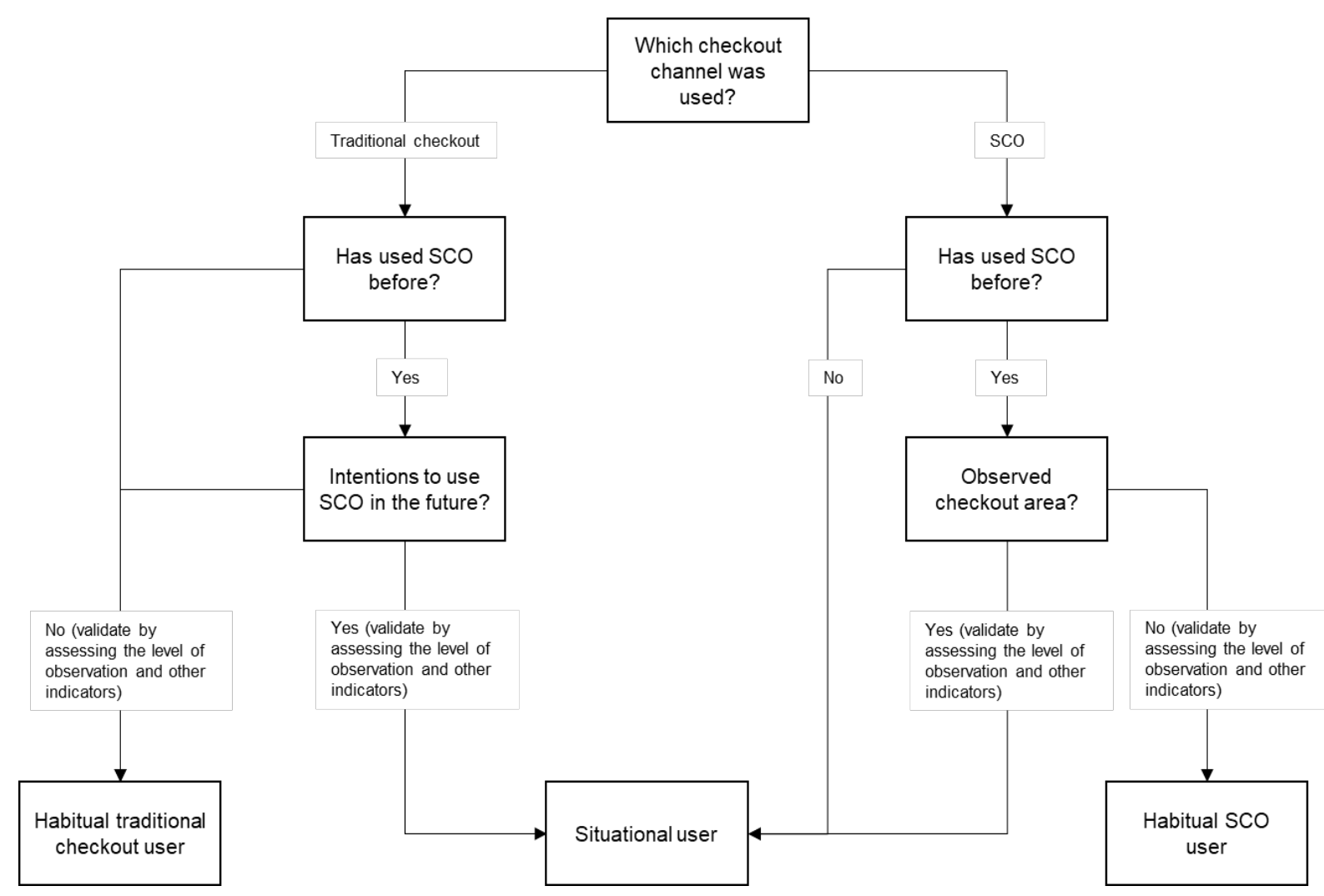

Figure 2. The classification system

To classify the traditional checkout users into habitual and situational user types, we checked whether they had any previous use experience with SCOs or intentions to use them in the future. If a customer has never used SCO and checks out through traditional till at the time of the interview, we concluded that $\mathrm{s} /$ he is using the traditional method out of habit. Although such customers might have intentions to try SCOs, they have not yet broken the habit of using the traditional tills. Thus, those customers who had never used SCOs before were preliminarily categorised as habitual traditional checkout users. Moreover, also the ones who reported having used SCOs before but had no intentions of using them again were considered to belong to the same group as trialling SCO had not caused them to break their habits. On the other hand, customers who reported having used SCOs before and expressed intentions of using them again were considered potential situational users. This classification was checked against the level of observation exercised at the checkout area so that high levels supported 
situational use. While these customers consider both checkout channels as viable options, this time they chose the traditional channel based on their reflection of the situation.

For self-checkout users, the initial division between habitual and situational users was established similarly, by first looking into their prior SCO experience and then their reported observation of the checkout area. The level of observation was an especially critical metric because the SCO channels in the stores of this study are designed so that there is always one queue to the SCO area that comprises of altogether five SCO tills. The next customer in the SCO queue gets to pay at the checkout as soon as anyone of the five tills becomes vacant. Thus, if the customer is habitually choosing SCO without further reflections, there is no need to specifically observe neither the SCO area nor the overall checkout area. However, if a customer reports having observed queues and other factors at the checkout area, that indicates that the customer has contemplated on whether to choose SCO or traditional checkout. As such, the ones who did not observe the checkout area were classified as habitual SCO users and the ones who observed the area as situational users.

Third, we triangulated the initial classifications by analysing other indicators and notes taken of the customers' elaborations. We looked into the reported level of deliberation put into the checkout selection, whether the selection was considered perfunctory, the point in time which the customer told having made the choice, motivations for choosing one channel and not the other, along with other relevant data.

For instance, low level of observation and knowing which checkout channel to use already before entering the store coupled with strong beliefs that SCO is a faster or more convenient checkout method supported habitual SCO use behaviour, as illustrated by Customer A in the example below:

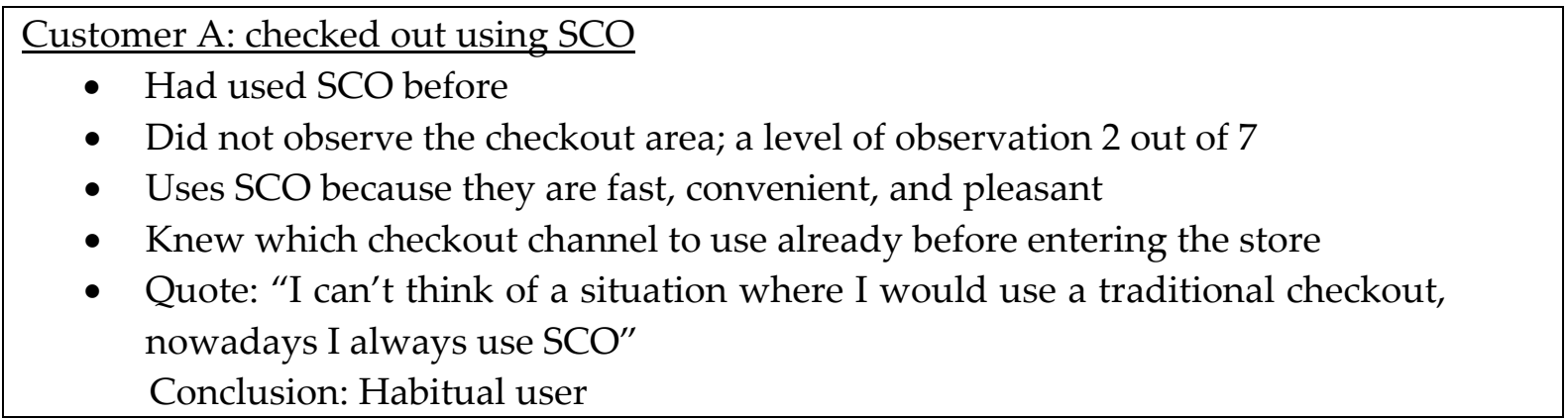

Then again, reflective situational behaviour was associated with a high level of observation and statements that emphasized the situational nature of the choice:

Customer B: checked out using SCO

- Had used SCO before

- Observed the checkout area; a level of observation 7 out of 7

- Likes SCO because they are fast and allow simultaneous scanning and packing

- Did not know which checkout channel to use before entering the checkout area

- Quote: "I would use traditional checkout if it had no queue and if I had only a couple of items"

Conclusion: Situational user 
Moreover, visual mapping of the customer journey at the checkout area helped to verify the analysis: while the drawings showed some customers marching straight to their chosen checkout lane without hesitation, others appeared to halt for a second to observe and process the situation before making the choice. Appendix B provides exemplary customer vignettes that demonstrate how classifications were reached. The classifications were first done independently by each author of this manuscript according to the principles outlined above. To assess the interrater reliability (i.e., the agreement among raters), we ran Cohen's kappa in SPSS to determine the extent to which the two authors agreed in their classifications (Landis \& Koch, 1977). It yielded a $\kappa$-value of 0.868 ( $\mathrm{p}<0.001)$, which means a percent agreement of $86.8 \%$. This indicates that the two raters were not in agreeance about $13.2 \%(1-0.868)$ of the classifications. While a $\kappa$-value of 0.868 represents almost perfect agreement (Landis \& Koch, 1977) and signals of sufficient interrater reliability, we discussed the differences in classifications until a full agreement was reached.

\section{Findings}

After analysing the data in line with the principles described above, three distinct types of customers emerged as expected: habitual traditional checkout users, habitual SCO users, and situational users (who checked out using either traditional checkout or SCO). In addition, a fourth customer type was discovered whose checkout selection behaviour did not fit into the initial categories. This fourth type was named as drifting users. The resulting customer types are summarised in Table 2. Next, the characteristics of the discovered customer types are discussed.

\begin{tabular}{|c|c|c|c|c|c|}
\hline Customer type & $n$ & $\begin{array}{l}\text { Choice ratio } \\
\text { (SCO vs. } \\
\text { traditional) }\end{array}$ & $\begin{array}{c}\begin{array}{c}\text { Number } \\
\text { of } \\
\text { purchases }\end{array} \\
\end{array}$ & $\begin{array}{l}\text { Observation } \\
\text { at the } \\
\text { checkout area }\end{array}$ & $\begin{array}{l}\text { Most common reasons for the } \\
\text { current checkout choice }\end{array}$ \\
\hline $\begin{array}{l}\text { Habitual } \\
\text { traditional } \\
\text { checkout users }\end{array}$ & 12 & $0 \%-100 \%$ & 4.9 & $\begin{array}{c}\text { Moderate } \\
\text { (mean 4.6, } \\
\text { sd 2.5) }\end{array}$ & $\begin{array}{c}\text { Habit; wants to preserve cashier } \\
\text { jobs; no prior experience of SCO; } \\
\text { human contact }\end{array}$ \\
\hline $\begin{array}{l}\text { Habitual SCO } \\
\text { users }\end{array}$ & 11 & $100 \%-0 \%$ & 6.9 & $\begin{array}{c}\text { Low } \\
\text { (mean 1.7, } \\
\text { sd 0.9) }\end{array}$ & $\begin{array}{c}\text { Speed of checkout; handy; } \\
\text { usually no queue }\end{array}$ \\
\hline Situational users & 44 & $61 \%-39 \%$ & 6.0 & $\begin{array}{c}\text { High } \\
\text { (mean 5.7, } \\
\text { sd 1.6) }\end{array}$ & $\begin{array}{l}\text { Length of the queue at the time } \\
\text { of checking out; speed of } \\
\text { checkout; situational need }\end{array}$ \\
\hline Drifting users & 2 & $50 \%-50 \%$ & 4.0 & $\begin{array}{l}\text { Low/moderate } \\
\text { (mean 3.0, } \\
\text { sd 2.8) } \\
\end{array}$ & Happened to be near; no queue \\
\hline Total sample & 69 & $57 \%-43 \%$ & 5.9 & & \\
\hline
\end{tabular}

Table 2. The resulting customer types

\subsection{Habitual traditional checkout users}

Most of the habitual traditional checkout users had never tried SCOs, and when asked whether they intend to do so, their response was either 'no' or 'possibly'. Although two of them had tried SCOs in the past, they stated not intending to use them again. Thus, most habitual traditional checkout users have not yet broken their incumbent habit by trialling SCOs - and the ones who have done that have concluded that they prefer to stick with the traditional service. Interestingly, these customers reported moderate levels of observation (on average 4.6 
out of $7, \mathrm{SD}=2.5$ ) at the checkout area. This can be explained by the insight that some of them were contemplating on which one of the traditional checkouts to choose. Additional measures and the high standard deviation in reported observation levels lend support to this notion.

These customers expressed the most diverse set of reasons for selecting traditional checkout. The most cited reasons were incumbent habit and lack of prior experience of SCO use. Moreover, these customers want effortless personal service and human contact, and they are often worried about making errors when operating them. Furthermore, many stated their concern about cashier jobs disappearing due to the emergence of technologies like SCO. Finally, habitual traditional checkout users may want to use cash and buy cigarettes, which can only be done at traditional checkout, and this reinforces them to stick with their incumbent habits. When asked what would make them choose SCO instead, some stated that they would not use SCO in any circumstances, while others said that they might consider using SCO in the case of prohibitively long queues to the traditional checkouts. These customers waited in line for 2:25 minutes on average and represented the oldest people in the sample with an average age of 50 .

\subsection{Habitual SCO users}

Habitual SCO users use SCO automatically whenever it is available. All such customers in the sample had prior experience of using SCOs and they intended to continue using the technology in the future too. They described their checkout selection as perfunctory and reported of not having observed any environmental factors in the checkout area. This was confirmed by their low reported average rate of observation ( 1.7 out of $7, \mathrm{SD}=0.9)$. The most often mentioned reason for selecting SCO was their general belief that SCOs offer speedier checkout and that they do not usually have queues. These assumptions appeared to be behind forming the habit of SCO use. The data supports their belief: habitual SCO users waited in line only for 0:11 minutes on average. Other reasons were related to convenience, privacy, control, and fun provided by SCOs. When asked, what would make them choose traditional checkout instead, most stated that they would do that only if SCOs were not available at all or that they would have to buy something that is not available at SCO. The average age in this group was 41 years.

\subsection{Situational users}

Situational users rarely have any predetermined checkout choices in mind when they walk into the store - instead, they tend to make their final decision at the checkout area. These customers reported consistently high levels of observation at the checkout area (5.7 out of 7, $\mathrm{SD}=1.6$ ), and ended up making non-perfunctory choices more often than others. Everyone had previous experience of SCO use, except for one customer who used SCO for the first time at the time of the interview.

Situational users had highly circumstantial motives for choosing between technology and human-delivered service. Those who chose traditional service did that because the queue was short, they wanted to use cash, or needed to buy something that is not available at SCO (e.g., cigarettes, stamps). Those situational users who chose SCO this time mentioned short queues and a small number of purchases as the main motivations for their choice. However, the second most cited reason was a general belief that SCOs are faster. Situational users were generally willing to make a different choice of checkout than they did at the time of the interview if the situation would require so: both checkout alternatives were considered as 
viable options. Some customers in this group reported normally paying more attention to the checkout selection but this time their choice was exceptionally impulsive due to certain internal or external triggers (e.g., tiredness, shopping companion, or receiving a phone call) that inhibited the functioning of their reflective system. It appears that leveraging the reflective system bears fruit in terms of efficiency: situational users queued only for 0:33 minutes on average. The average age of a situational user was 34 years.

\subsection{Drifting users}

Two customers reported simply 'drifting' to the closest checkout (SCO or traditional) without paying any attention to queues or other factors in the surroundings. Thus, these customers appeared surprised when prompted with questions about their checkout selection - they had not even thought about making a choice. They further emphasized that while they made no cognitive efforts to choose the optimal service option - neither this time nor in general - they also do not have a routine or habit of whatsoever regarding checkout selection. Instead, they end up to the nearest checkout available, no matter if it is a traditional or an SCO till. Consistently, they exhibited low to moderate levels of observation at the checkout area and had no previously established intentions regarding choosing the checkout method at the time of shopping, but both had used SCO before and intended doing so in the future too - if they would happen to drift to the self-service tills. These users represented the younger end of the sample with an average age of 27 years.

\section{Discussion}

Our analysis reveals the occurrence of both extreme reflective and reflexive processing and interesting nuances in between them. Customers can apply deliberate reasoning through high levels of reflective processing (situational users) or make the decision entirely automatically relying on reflexive instincts (drifting users). In between these extremes are the habitual users who automatically go to either SCOs or traditional tills, and thus do not need much situational reflection regarding the choice between SST and human service due to their habit, beliefs, or attitude.

Habitual traditional checkout users exhibited a strong habit of using the traditional service and seemed unlikely to deviate from it. Those traditional checkout users who had no prior experience in SCO use exhibited inertia in technology adoption (Polites \& Karahanna, 2012) the reason for not using SCOs was - paradoxically - often reported to stem from the lack of prior SCO use. The ones who had tried SCO in the past expressed no intentions to return using SCOs in the future, suggesting that their first trials were disappointing, indicating unsuccessful recovery from a service failure (Collier, Breazeale, \& White, 2017). Similarly, in line with previous findings (Wang et al., 2013, 2017), incumbent habit and established beliefs of SCOs' efficiency emerged as strong drivers of habitual SCO use. The convenience of SCOs may have decreased these customers' need for human interaction (Chen et al., 2018; Collier \& Kimes, 2012), as the users have been able to substitute traditional service almost entirely with the SST. Habitual traditional checkout users were older than habitual SCO users, which is in line with previous findings indicating that younger people are more prone to adopt SSTs (Dean, 2008).

By contrast, situational users continuously employ reflective processing in their search for an optimal choice. The selection is made based on a reflective evaluation of the observed situational factors at the checkout area and the users' current needs and preferences, making 
situational users' checkout selection harder to predict than that of habitual ones. The different motivations behind checkout selection between habitual SCO users and situational users corroborate this: while the former ones usually referred to their general belief of SCOs being a fast checkout method as the main motivation for selecting SCO, the latter group tended to emphasize the current queue situation or the crowdedness (Collier et al., 2015; Gelderman et al., 2011) of the checkout area.

Finally, certain individuals do not apply any kind of (conscious) cognitive processing but go to any checkout that is available nearby. However, one should consider the possibility that through experience they have found that neither forming a habit nor using constant optimisation helps them to make better choices, and thus they have stopped using their cognitive resources for such daily dilemmas.

Consumer choice behaviour lies at disciplinary crossroads where advancements in our understanding continue to have important implications in diverse fields such as retailing, consumer services, psychology, strategic management, and marketing. The different consumer types put forth here provides implications to both researchers and practitioners. Our contributions, summarized in Table 3, will be discussed next.

\begin{tabular}{|l|l|l|}
\hline Literature stream & What we knew & What we now know \\
\hline Consumer research & $\begin{array}{l}\text { Consumers can be classified into different } \\
\text { types based on, e.g., the temporality of } \\
\text { their technology adoption (Rogers, 2003), } \\
\text { the extent of technology use (Shih \& } \\
\text { Venkatesh, 2004), and consumption styles } \\
\text { (Friedrich \& Zanker, 2011). }\end{array}$ & $\begin{array}{l}\text { Consumers can be classified into different } \\
\text { types based on how they choose between SST } \\
\text { and human-delivered service. At least four } \\
\text { types exist in the context of retail SCO: } \\
\text { habitual traditional checkout users, habitual } \\
\text { SCO users, situational users, and drifting } \\
\text { users. }\end{array}$ \\
\hline SST research & $\begin{array}{l}\text { Situational factors such as waiting time } \\
\text { and crowdedness influence SST use } \\
\text { decisions (Collier et al., 2015; Gelderman } \\
\text { et al., 2011). }\end{array}$ & $\begin{array}{l}\text { Situational factors shape the choices of } \\
\text { situational users but have little effect on } \\
\text { habitual users. The latter ones are heavily } \\
\text { driven by their learned habits. }\end{array}$ \\
$\begin{array}{l}\text { Habit drives SST use (Wang et al., 2013, } \\
\text { 2017). }\end{array}$ & $\begin{array}{l}\text { Drifting users neither process situational } \\
\text { factors nor adhere to particular habits; their } \\
\text { decisions are shaped by the environment } \\
\text { without their active awareness. }\end{array}$ \\
\hline $\begin{array}{l}\text { Technology } \\
\text { acceptance research }\end{array}$ & $\begin{array}{l}\text { Technology use is explained by } \\
\text { perceptions of technology such as } \\
\text { usefulness and ease of use, and individual } \\
\text { traits such as technology readiness, self- } \\
\text { efficacy, and computer playfulness (Blut } \\
\text { et al., 2016; Venkatesh et al., 2012). }\end{array}$ & $\begin{array}{l}\text { Individual propensity to simplify or optimise } \\
\text { daily choices shapes technology use } \\
\text { behaviour, as technology is increasingly } \\
\text { present in different aspects of daily life. }\end{array}$ \\
\hline
\end{tabular}

Table 3. Contributions of the study

\subsection{Theoretical implications}

First, to our best knowledge, this is the first study that produces a typology of consumers based on their decision-making behaviour when selecting between SST and human-delivered service. We provide a typology of consumers based on the extent to which they are driven or affected by situational factors and habits. The findings corroborated our initial intuition that consumers do differ in this respect: some tend to perform deliberate processing while others operate automatically. By shedding light on the interplay of situational factors and habits with 
different types of consumers, this study deepens the current understanding of how such forces shape consumer behaviour in a retail setting. Our typology resonates with that of Shih and Venkatesh (2004), who classified consumers into four groups based on the variety and rate of their technology use: intense, specialized, nonspecialized, and limited. Our approach is different in that we focused on the choice situation instead of general technology perceptions, leading us to distinguish contextualized use behaviours.

Second, the study contributes to the rich stream of literature on retail SSTs (Amorim et al., 2016; Collier et al., 2015; Lien et al., 2019; Vannucci \& Pantano, 2019) and, specifically, on the consumer choice problem of selecting between an SCO and a traditional checkout (Gelderman et al., 2011). To this end, we demonstrate the usefulness of the dual-system approach when studying such decision-making. We show that neither situational factors nor habits exert their effects uniformly across the consumer pool, but their effects vary between consumer groups. We also distinguish an unexpected type of consumer that we refer to as drifting users. Our interpretation of this finding is that choosing not to make a deliberate choice - whether the latter choice would involve establishing and following a habit reflexively or exercising conscious reflection every time - could serve as a method of increasing one's well-being. Accordingly, both drifting users exhibited high satisfaction with their choice. This is interesting as it contradicts Dijksterhuis et al's (2006) finding that conscious processing of simple decisions (which checkout selection arguably is) would result in higher post-choice satisfaction than giving them only a little attention. Dhar and Gorlin (2013) note that "when two options are equally attractive, justification does not provide a clear reason for choosing one versus the other." Thus, when a consumer has neither an incumbent preference over the checkout method nor the desire to optimise the selection, choice deferral in the form of drifting could be expected to happen. Overall, studying drifting users warrants further research efforts.

Third, our findings provide novel perspectives on technology acceptance research in general. Our typology connects to Rogers' (2003) stages of innovation adoption (e.g., exposure, adoption, continued use) in that situational technology use seems to occur more prevalently in the early stages of technology introduction as some consumers are still seeking the optimal balance between use and non-use. Later a specific segment of users then matures into habitual technology users. While technology introduction can often disrupt consumer behaviour, it appears that consumers' inherent traits influence their behaviours above and beyond a specific technology.

Thus, the use of cognitive processing with regard to the use of technology appears to be influenced not only by technology's characteristics but also by customers' inherent preferences between simplicity and optimisation in daily life decisions. While simplifiers look for easy solutions for accomplishing a task, optimisers are willing to strive to find the best solution possible, even if that would incur additional cognitive workload or even stress (Adams, 2013). This brings an additional perspective to Simon and Usunier's (2007) finding that the choice between SST and human service is influenced by the extent to which consumer exhibits rational or experiential thinking style. For instance, habitual SCO users may have been optimisers to a certain point but after enough reflection they have preferred to solidify the most optimal mode of behaviour into a habit, perhaps to save cognitive resources. On the contrary, situational users may not settle for the solution that is the most optimal on average - instead, they remain optimisers to the very end. To some extent, this optimisation seems to 
pay off, since the waiting times were observed low among both situational users and habitual SCO users. This could relate to the paradox of choice: having more options to choose from leads to worse satisfaction with one's choices due to increased expectations and heightened regrets, and thus having a plethora of choices can have a paralysing effect on one's decisionmaking (Schwartz, 2004).

\subsection{Managerial implications}

Identifying customer types can help retailers to distinguish the critical issues that should be considered when implementing SSTs. This study's findings highlight the importance of understanding different customer types when managing staffing and store layout. Considering that most consumers appear to be situational users, it might make sense for retailers to focus on catering to this segment. However, interviews with the store managers revealed that customers' SCO utilization rates tend to be below their desired levels. The manager of Site A explained that while a satisfactory utilization rate would be at $30 \%$ of all customers checking out through SCOs, that rate has remained between $25-27 \%$ in the store. Similarly, the SCO utilization rate at Site B was reported as low as $20 \%$ of all the customer checkouts (and 16-17\% of the aggregate transaction volumes). Thus, it may be in the interest of store management to increase the number of SCO users. This could happen at least in two ways: 1) getting habitual traditional checkout users to trial SCOs, and through that turn them into situational users, and possibly later even into habitual SCO users, and 2) prompting situational and drifting users to choose SCO more often. These objectives can be advanced by occasionally increasing the number of service staff at the SCO area who can then invite people to try SCOs and provide assistance with operating them. Moreover, layout accessibility has been found to significantly affect customers' satisfaction with a retail environment (Wakefield \& Blodgett, 1996). Thus, SCOs could be made more accessible through careful design of store layout by situating them so that people are easily prompted to use them. Finally, recent research has discussed the significance of service providers being clear about their motivations for the SST introduction (Nijssen, Schepers, Jeroen, \& Belanche, 2016), suggesting that retailers should emphasize their position on the matter, which is often that SCOs are not introduced to substitute human employees but rather to provide better service for customers.

\subsection{Limitations and avenues for future research}

This study comes with a number of limitations that need to be addressed. First, one might reasonably assume that most of the customers in the sample were not in a terrible hurry during their shopping trip, since they had time to be interviewed. If this is true, the sample may be biased toward customers whose checkout selection was not affected by hurry. However, when inviting customers for an interview, the interview's brevity and the importance of participation were emphasized. In addition, a few informants that mentioned being in a bit of a hurry still found time to respond to the questionnaire, so this limitation should not severely impact the results.

Second, regarding self-reported SCO use intentions, it is possible that some customers (especially traditional checkout users) responded in a socially desirable way to avoid coming across as technology laggards (Rogers, 2003). Thus, it could be that their behavioural intentions to use SCO are lower in reality. Moreover, sometimes intentions may not translate into actual behaviour due to strong incumbent habits (in any given customer group), and thus using them as proxies for future behaviour should be exercised with some reservations. 
Finally, our method of assessing the dominance between the two cognitive processing systems is somewhat crude and may lack some relevant components, limiting our ability to make conclusions of cognitive processes. However, we do believe that we managed to capture notions of reflective and reflexive processing in a way that it sufficiently accurate for our purposes of producing a consumer typology. We made significant efforts to ensure the validity of our data and analytical outcomes by informing ourselves of the existing dual-system theories, brainstorming different approaches to capture the reasoning process, and pilot testing the questionnaire. While the currently available technology does not provide noninvasive ways to get inside of customers' heads to observe their thought processes, the applied research instrument could be refined further. Future research can also extend the research scope by studying the interplay of characteristic thinking styles and situational processing. This could yield a clearer overall picture of the forces that influence customers' choices.

\section{References}

Aarts, H., \& Dijksterhuis, A. (2000). Habits as knowledge structures: automaticity in goaldirected behavior. Journal of Personality and Social Psychology, 78(1).

Adams, S. (2013). How to Fail at Almost Everything and Still Win Big: Kind of the Story of My Life. Portfolio.

Amorim, M., Lago, A., Moscoso, P., \& Prieto, E. (2016). Assisted vs. self-checkout in retail: An empirical analysis of the impact of operational process dimensions on customer satisfaction, recommendation and reuse. Journal of Service Science Research, 8(1), 1-39. https://doi.org/10.1007/s12927-016-0001-z

Atapattu, M., Sedera, D., \& Ravichandran, T. (2014). Agility in consumer retail: Sense-response alignment through the eyes of customers. Australasian Journal of Information Systems, 18(2), 111-132. https://doi.org/10.3127/ajis.v18i2.866

Beatson, A., Lee, N., \& Coote, L. V. (2007). Self-service technology and the service encounter. The Service Industries Journal, 27(1), 75-89. https://doi.org/10.1080/02642060601038700

Bertacchini, F., Bilotta, E., \& Pantano, P. (2017). Shopping with a robotic companion. Computers in Human Behavior, 77, 382-395. https://doi.org/10.1016/j.chb.2017.02.064

Bitner, M. J., Booms, B. H., \& Tetreault, M. S. (1990). The service encounter: Diagnosing favorable and unfavorable incidents. Journal of Marketing, Vol. 54, pp. 71-82. https://doi.org/10.2307/1252074

Blut, M., Wang, C., \& Schoefer, K. (2016). Factors Influencing the Acceptance of Self-Service Technologies: A Meta-Analysis. Journal of Service Research, 19(4), 396-416. https://doi.org/10.1177/1094670516662352

Bond, S. D., Bettman, J. R., \& Luce, M. F. (2009). Consumer Judgment from a Dual-Systems Perspective: Recent Evidence and Emerging Issues. In Review of Marketing Research (pp. 3-37).

Brandtzæg, P. B., \& Heim, J. (2011). A typology of social networking sites users. International Journal of Web Based Communities, 7(1), 28-51. https://doi.org/10.1504/IJWBC.2011.038124

Broniarczyk, S. M., \& Griffin, J. G. (2014). Decision Difficulty in the Age of Consumer 
Empowerment. Journal of Consumer Psychology, 24(4), 608-625. https://doi.org/10.1016/j.jcps.2014.05.003

Chen, C., White, C., \& Hsieh, Y. E. (2020). The role of consumer participation readiness in automated parcel station usage intentions. Journal of Retailing and Consumer Services, 54(October 2019), 102063. https://doi.org/10.1016/j.jretconser.2020.102063

Chen, Y., Yu, J., Yang, S., \& Wei, J. (2018). Consumer's intention to use self-service parcel delivery service in online retailing: An empirical study. Internet Research, 28(2), 500-519. https://doi.org/10.1108/IntR-11-2016-0334

Collier, J., Breazeale, M., \& White, A. (2017). Giving back the "self" in self service: customer preferences in self-service failure recovery. Journal of Services Marketing, 31(6), 604-617. https://doi.org/10.1108/JSM-07-2016-0259

Collier, J., \& Kimes, S. (2012). Only If It Is Convenient: Understanding How Convenience Influences Self-Service Technology Evaluation. Journal of Service Research, 16(1), 39-51. https://doi.org/10.1177/1094670512458454

Collier, J., Moore, R. S., Horky, A., \& Moore, M. L. (2015). Why the little things matter: Exploring situational influences on customers' self-service technology decisions. Journal of Business Research, 68(3), 703-710. https://doi.org/10.1016/j.jbusres.2014.08.001

Collier, J., Sherrell, D., Babakus, E., \& Horky, A. (2014). Understanding the differences of public and private self-service technology. Journal of Services Marketing, 28(1), 60-70. https://doi.org/10.1108/JSM-04-2012-0071

Dean, D. H. (2008). Shopper age and the use of self-service technologies. Managing Service Quality: An International Journal, 18(3), 225-238. https://doi.org/10.1108/09604520810871856

Dhar, R., \& Gorlin, M. (2013). A dual-system framework to understand preference construction processes in choice. Journal of Consumer Psychology, 23(4), 528-542. https://doi.org/10.1016/j.jcps.2013.02.002

Dijksterhuis, A., Bos, M. W., Nordgren, L. F., \& van Baanen, R. B. (2006). On Making the Right Choice: The Deliberation-Without-Attention Effect. Science, 311, 1005-1008. https://doi.org/10.1126/science.1121629

Djelassi, S., Diallo, M. F., \& Zielke, S. (2018). How self-service technology experience evaluation affects waiting time and customer satisfaction? A moderated mediation model. Decision Support Systems, 111(August 2017), 38-47. https://doi.org/10.1016/j.dss.2018.04.004

Epstein, S. (1994). Integration of the Cognitive and the Psychodynamic Unconscious. American Psychologist, 49(8), 709-724. https://doi.org/10.1037/0003-066X.50.9.799

Epstein, S., Pacini, R., Denes-Raj, V., \& Heier, H. (1996). Individual differences in intuitiveexperiential and analytical-rational thinking styles. Journal of Personality and Social Psychology, 71(2), 390-405. https://doi.org/10.1037/0022-3514.71.2.390

Evanschitzky, H., Iyer, G. R., Pillai, K. G., Kenning, P., \& Schütte, R. (2015). Consumer Trial, Continuous Use, and Economic Benefits of a Retail Service Innovation: The Case of the Personal Shopping Assistant. Journal of Product Innovation Management, 32(3), 459-475. 
Friedrich, G., \& Zanker, M. (2011). A Taxonomy for Generating Explanations in Recommender Systems. AI Magazine, 32(3), 90. https://doi.org/10.1609/aimag.v32i3.2365

Galletta, D. F., Durcikova, A., Everard, A., \& Jones, B. M. (2005). Does spell-checking software need a warning label? Communications of the ACM, 48(7), 82-86. https://doi.org/10.1145/1070838.1070841

Gawronski, B. (2013). What should we expect from a dual-process theory of preference construction in choice? Journal of Consumer Psychology, 23(4), 556-560. https://doi.org/10.1016/j.jcps.2013.04.007

Gelderman, C. J., Ghijsen, P. W. T., \& van Diemen, R. (2011). Choosing self-service technologies or interpersonal services-The impact of situational factors and technology-related attitudes. Journal of Retailing and Consumer Services, 18, 414-421. https://doi.org/10.1016/j.jretconser.2011.06.003

Gorlin, M., \& Dhar, R. (2013). Refining the dual-process theory of preference construction: A reply to Gawronski, Martin and Sloman, Stanovich, and Wegener and Chien. Journal of Consumer Psychology, 23(4), 564-568.

Kahneman, D. (2003). Maps of Bounded Rationality: Psychology for Behavioral Economics. The American Economic Review, 93(5), 1449-1475. https://doi.org/10.1257/000282803322655392

Kahneman, D. (2011). Thinking, Fast and Slow. https://doi.org/10.1017/CBO9781107415324.004

Kurnia, S., Belts, J., \& Johnston, R. (2002). Understanding the Diffusion of Efficient Consumer Response: an Australian survey study. Australasian Journal of Information Systems, 9(2), 113-122. https://doi.org/10.3127/ajis.v9i2.198

Landis, J. R., \& Koch, G. G. (1977). The Measurement of Observer Agreement for Categorical Data. Biometrics, 33(1), 159-174. https://doi.org/10.2307/2529310

Laureiro-Martínez, D., \& Brusoni, S. (2018). Cognitive Flexibility and Adaptive DecisionMaking: Evidence from a laboratory study of expert decision-makers. Strategic Management Journal, 39(4), 1031-1058. https://doi.org/10.1002/smj.2774

Lee, H., \& Lyu, J. (2016). Personal values as determinants of intentions to use self-service technology in retailing. Computers in Human Behavior, 60, 322-332. https://doi.org/10.1016/j.chb.2016.02.051

Li, H., Guo, Y., \& Yu, Q. (2019). Self-control makes the difference: The psychological mechanism of dual processing model on internet addicts' unusual behavior in intertemporal choice. Computers in Human Behavior, 101(July), 95-103. https://doi.org/10.1016/j.chb.2019.07.010

Liao, S., \& Cheng, C. C. (2013). Consumer evaluation of self-service innovation failure: the effect of brand equity and attribution. The Service Industries Journal, 33(5), 467-485. https://doi.org/10.1080/02642069.2011.614339

Lieberman, M. D. (2007). Social Cognitive Neuroscience: A Review of Core Processes. Annual Review of Psychology, 58(1), 259-289. https://doi.org/10.1146/annurev.psych.58.110405.085 654

Lien, C. H., Hsu, M. K., Shang, J. Z., \& Wang, S. W. (2019). Self-service technology adoption by 
air passengers: a case study of fast air travel services in Taiwan. Service Industries Journal, 0(0), 1-25. https://doi.org/10.1080/02642069.2019.1569634

Liljander, V., Gillberg, F., Gummerus, J., \& van Riel, A. (2006). Technology readiness and the evaluation and adoption of self-service technologies. Journal of Retailing and Consumer Services, 13(3), 177-191. https://doi.org/10.1016/j.jretconser.2005.08.004

Limayem, M., Hirt, S. G., \& Cheung, C. M. K. (2007). How Habit Limits the Predictive Power Intention: The Case of Information Systems Continuance. MIS Quarterly, 31(4), 705-737.

Louis, M. R., \& Sutton, R. I. (1991). Switching Cognitive Gears: From Habits of Mind to Active Thinking. Human Relations, 44(1), 55-76.

Martin, J. W., \& Sloman, S. A. (2013). Refining the dual-system theory of choice. Journal of Consumer Psychology, 23(4), 552-555. https://doi.org/10.1016/j.jcps.2013.04.006

Meuter, M. L., Bitner, M. J., Ostrom, A. L., \& Brown, S. W. (2005). Choosing Among Alternative Service Delivery Modes: An Investigation of Customer Trial of Self-Service Technologies. Journal of Marketing, 69(2), 61-83. https://doi.org/10.1509/jmkg.69.2.61.60759

Meuter, M. L., Ostrom, A. L., Roundtree, R. I., \& Bitner, M. J. (2000). Self-Service Technologies: Understanding Customer Satisfaction with Technology-Based Service Encounters. Journal of Marketing, 64(July), 50-64. https://doi.org/10.1509/jmkg.64.3.50.18024

Meyers-Levy, J., \& Maheswaran, D. (2004). Exploring Message Framing Outcomes When Systematic, Heuristic, or Both Types of Processing Occur. Journal of Consumer Psychology, 14(1\&2), 159-167. https://doi.org/10.1207/s15327663jcp1401\&amp;2_18

Nijssen, E. J., Schepers, Jeroen, J. L., \& Belanche, D. (2016). Why did they do it? How customers' self-service technology introduction attributions affect the customer-provider relationship. Journal of Service Management, 27(3), 276-298.

Ortiz de Guinea, A., \& Markus, M. L. (2009). Why Break the Habit of a Lifetime? Rethinking the Roles of Intention, Habit, and Emotion in Continuing Information Technology Use. MIS Quarterly, 33(3), 433-444.

Osatuyi, B., \& Turel, O. (2018). Tug of war between social self-regulation and habit: Explaining the experience of momentary social media addiction symptoms. Computers in Human Behavior, 85, 95-105. https://doi.org/10.1016/j.chb.2018.03.037

Parasuraman, A. (2000). Technology Readiness Index (TRI): A Multiple-Item Scale to Measure Readiness to Embrace New Technologies. Journal of Service Research, 2(4), 307-320. https://doi.org/10.1177/109467050024001

Parasuraman, A., \& Colby, C. L. (2015). An Updated and Streamlined Technology Readiness Index: TRI 2.0. Journal of Service Research, 18(1), 59-74. https://doi.org/10.1177/10946705145 39730

Penttinen, E., Rinta-Kahila, T., Ronkko, M., \& Saarinen, T. (2014) Triggering Intention to Use to Actual Use--Empirical Evidence from Self-Service Checkout (SCO) Systems. Proceedings of the 47th Hawaii International Conference on System Sciences, 3347-3355.

Polites, G., \& Karahanna, E. (2012). Shackled to the Status Quo: The Inhibiting Effects of Incumbent System Habit, Switching Costs, and Inertia on New System Acceptance. MIS Quarterly, 36(1), 21-42. 
Polkinghorne, D. E. (2005). Language and meaning: Data collection in qualitative research. Journal of Counseling Psychology, Vol. 52, pp. 137-145. https://doi.org/10.1037/00220167.52.2.137

Rinta-Kahila, T., Penttinen, E., Kumar, A., \& Janakiraman, R. (2021). Customer reactions to self-checkout discontinuance. Journal of Retailing and Consumer Services, 61, 102498. https://doi.org/10.1016/j.jretconser.2021.102498

Rogers, E. M. (2003). Diffusion of Innovations (5th edition). New York: Free Press.

Roy, S. K., Balaji, M. S., Sadeque, S., Nguyen, B., \& Melewar, T. C. (2017). Constituents and consequences of smart customer experience in retailing. Technological Forecasting and Social Change, 124(2017), 257-270. https://doi.org/10.1016/j.techfore.2016.09.022

Schwartz, B. (2004). The Paradox of Choice. Harper Perennial.

Shih, C.-F., \& Venkatesh, A. (2004). Beyond adoption: Development and application of a use$\begin{array}{lll}\text { diffusion model. Journal of } & \text { Marketing, }\end{array}$ https://doi.org/10.1509/jmkg.68.1.59.24029

Simon, F., \& Usunier, J.-C. (2007). Cognitive, demographic, and situational determinants of service customer preference for personnel-in-contact over self-service technology. International Journal of Research in Marketing, 24(2), 163-173. https://doi.org/10.1016/j.ijresar.2006.11.004

Sloman, S. A. (1996). The Empirical Case for Two Systems of Reasoning. Psychological Bulletin, 119(1), 3-22.

Soror, A. A., Hammer, B. I., Steelman, Z. R., Davis, F. D., \& Limayem, M. M. (2015). Good habits gone bad: Explaining negative consequences associated with the use of mobile phones from a dual-systems perspective. Information Systems Journal, 25(4), 403-427. https://doi.org/10.1111/isj.12065

Stanovich, K. E., \& West, R. F. (2000). Individual differences in reasoning: Implications for the rationality debate? Behavioral and Brain Sciences, 23(5), 645-665. https://doi.org/10.1017/S0140525X03210116

Turel, O., \& Qahri-Saremi, H. (2016). Problematic Use of Social Networking Sites: Antecedents and Consequence from a Dual-System Theory Perspective. Journal of Management Information Systems, 33(4), 1087-1116. https://doi.org/10.1080/07421222.2016.1267529

Vannucci, V., \& Pantano, E. (2019). Digital or human touchpoints? Insights from consumerfacing in-store services. Information Technology and People, 33(1), 296-310. https://doi.org/10.1108/ITP-02-2018-0113

Venkatesh, V., \& Morris, M. G. (2000). Why Don't Men Ever Stop to Ask for Directions? Gender, Social Influence, and Their Role in Technology Acceptance and Usage Behavior. MIS Quarterly, 24(1), 115-139.

Venkatesh, V., Thong, J. Y. L., \& Xu, X. (2012). Consumer Acceptance and Use of Information Technology: Extending the Unified Theory of Acceptance and Use of Technology. MIS Quarterly, 36(1), 157-178.

Verplanken, B., Aarts, H., \& VanKnippenberg, A. (1997). Habit, information acquisition, and the process of making travel mode choices. European Journal of Social Psychology, 27(5), 
539-560. https://doi.org/10.1002/(sici)1099-0992(199709/10)27:5<539::aid-ejsp831>3.0.co;2a

Verplanken, B., \& Wood, W. (2006). Interventions to Break and Create Consumer Habits. Journal of Public Policy \& Marketing, 25(1), 90-103.

Wakefield, K. L., \& Blodgett, J. G. (1996). The effect of the servicescape on customers' behavioral intentions in leisure service settings. Journal of Services Marketing, 10(6), 45-61. https://doi.org/10.1108/JSM-08-2016-0291

Wang, C., Harris, J., \& Patterson, P. (2012). Customer choice of self-service technology: the roles of situational influences and past experience. Journal of Service Management, 23(1), 54-78. https://doi.org/10.1108/09564231211208970

Wang, C., Harris, J., \& Patterson, P. (2013). The Roles of Habit, Self-Efficacy, and Satisfaction in Driving Continued Use of Self-Service Technologies: A Longitudinal Study. Journal of Service Research, 16(3), 400-414. https://doi.org/10.1177/1094670512473200

Wang, C., Harris, J., \& Patterson, P. (2017). Modeling the habit of self-service technology usage. Australian Journal of Management, 42(3), 462-481. https://doi.org/10.1177/03128962166408 62

Weijters, B., Rangarajan, D., Falk, T., \& Schillewaert, N. (2007). Determinants and Outcomes of Customers' Use of Self-Service Technology in a Retail Setting. Journal of Service Research, 10(1), 3-21. https://doi.org/10.1177/1094670507302990

Zarantonello, L., \& Schmitt, B. H. (2010). Using the brand experience scale to profile consumers and predict consumer behaviour. Journal of Brand Management, 17(7), 532-540. https://doi.org/10.1057/bm.2010.4

Zhu, Z., Nakata, C., Sivakumar, K., \& Grewal, D. (2013). Fix It or Leave It? Customer Recovery from Self-service Technology Failures. Journal of Retailing, 89(1), 15-29. https://doi.org/10.1016/j.jretai.2012.10.004

\section{Appendix A: The Data collection instrument}

The observation protocol is presented in Table A1. The layout depiction on the last row was used for tracking customers' movement in the checkout area. Letters A-G signify different aisles in the store that lead to the checkout area. The black box in the SCO area signifies the employee who supervises the SCO transactions.

\begin{tabular}{|l|l|}
\hline \multicolumn{2}{|c|}{ BACKGROUND INFO } \\
\hline $\begin{array}{l}\text { Date: } \\
\text { Time: }\end{array}$ & $\begin{array}{l}\text { Site: } \\
\text { Researcher: }\end{array}$ \\
\hline \multicolumn{2}{|c|}{ THE CUSTOMER } \\
\hline $\begin{array}{l}\text { Gender: } \\
\square \text { Man } \square \text { Woman }\end{array}$ & Additional information: \\
\hline Age: & \\
\hline \multicolumn{2}{|c|}{ THE CHECKOUT SITUATION } \\
\hline $\begin{array}{l}\text { Chosen checkout: } \\
\square \text { Traditional }\end{array}$ & $\begin{array}{l}\text { Shopping instrument: } \\
\square\end{array}$ \\
\hline
\end{tabular}




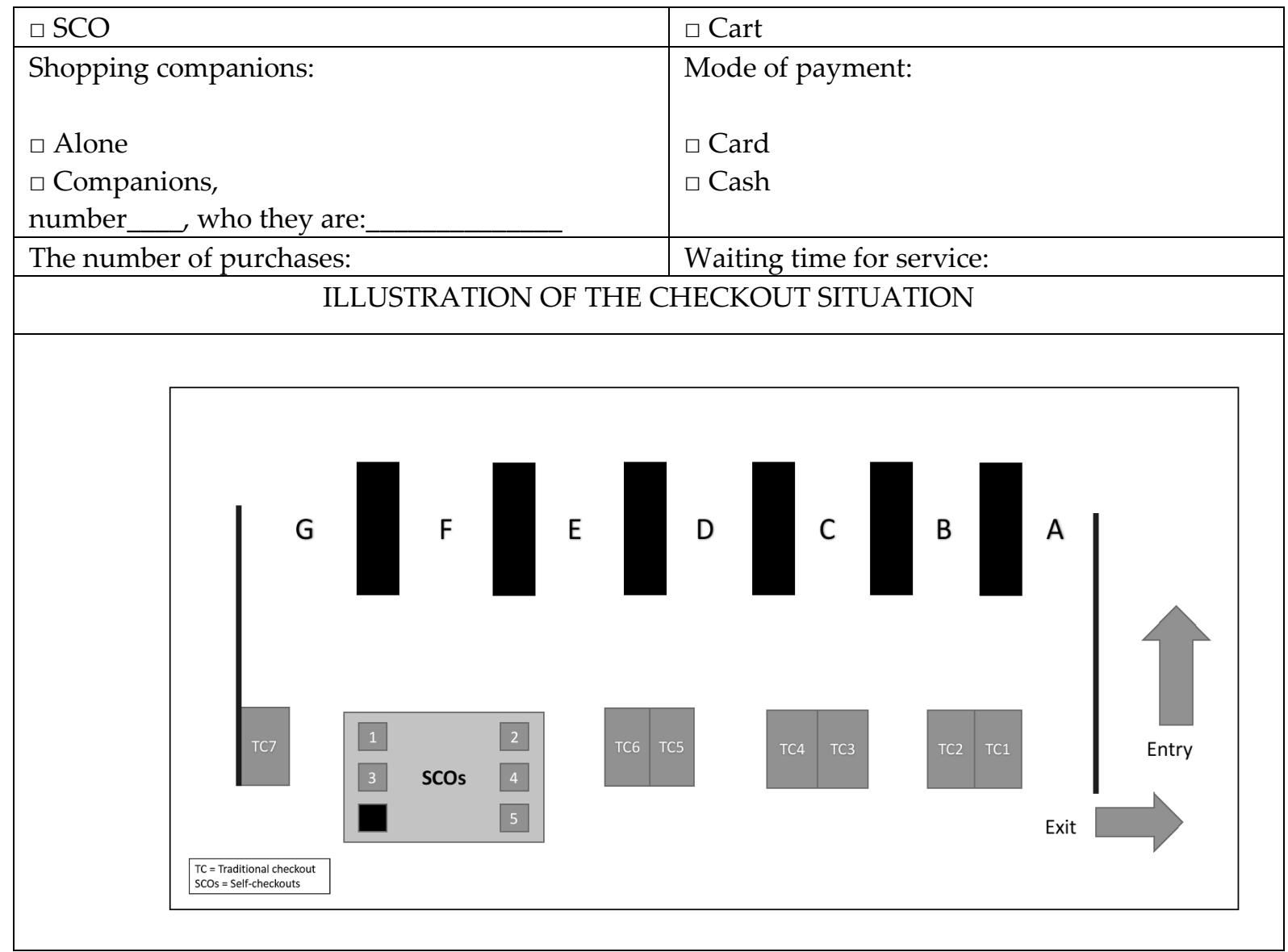

Table A1 The observation protocol

The interview protocol is presented in Table A2. Empty space around the questions and the backside of the form were leveraged when making additional notes.

\begin{tabular}{|c|}
\hline INTERVIEW QUESTIONS \\
\hline Was the shopping trip planned beforehand or did you just happen to stop by? \\
\hline Was this your first time in this particular grocery store? \\
\hline $\begin{array}{l}\text { 3. At which point did you decide whether to use traditional checkout or self-checkout? } \\
\square \text { Before entering the store } \\
\square \text { While shopping } \\
\square \text { At the checkout area }\end{array}$ \\
\hline $\begin{array}{l}\text { 4. Did you make observations of the checkout area (e.g., waiting lines, other customers' } \\
\text { purchases, available checkout lanes)? } \\
\square \text { Yes } \\
\square \text { No } \\
\text { Give an estimation between a range of } 1-7 \text {, where: } \\
\text { (1) I did not make any observations ... (7) I made a lot of observations }\end{array}$ \\
\hline $\begin{array}{l}5 . \quad \text { Why did you choose self-checkout / traditional checkout? Name the three most important } \\
\text { reasons and their relative importance }(0-100 \%) \text {. Are there any other reasons? }\end{array}$ \\
\hline $\begin{array}{l}\text { 6. In what kind of situation would you choose self-checkout / traditional checkout? Any other } \\
\text { reasons? }\end{array}$ \\
\hline
\end{tabular}




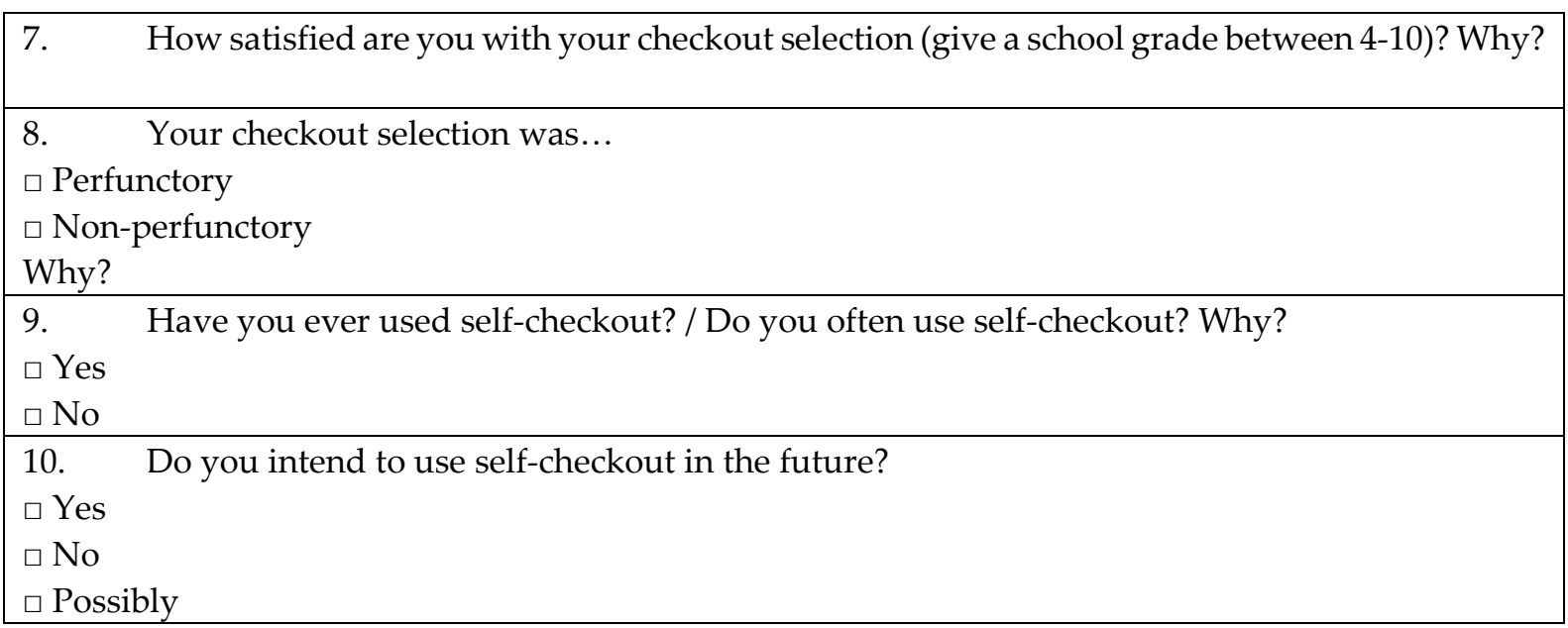

Table A2 The interview protocol

\section{Appendix B: Exemplary Customer Vignettes}

This appendix provides exemplary vignettes from the sample. In essence, it presents detailed depictions of customers from each group discussed in the Findings section. The purpose of this is to further elaborate on how these customers made their choice of checkout method, why they chose the checkout they used, and in which circumstances they would act otherwise.

\section{Habitual traditional checkout user (Site C)}

An 82-year old woman was shopping with her friend. At the checkout area, they bypassed the empty SCO area while proceeding towards traditional checkouts, scanning for a one with the shortest waiting line. Both women were using shopping trolleys and spent approximately two minutes in the queue before receiving service. The woman bought five items and paid them with cash.

She accepted the invitation to interview as they were not in a hurry. She explained that the decision to use a traditional checkout was already clear to her when entering the store, as she had never used SCOs and had no intention to try them. However, before starting to queue she consciously made a considerable amount of observations at the checkout area (5 out of 7) as she wanted to find a traditional checkout with the shortest queue. The incumbent habit was the most important reason (90\%) for selecting traditional checkout but she also mentioned preferring personal service $(10 \%)$. The only situation where she might use SCO would be if it was the only option available and that someone would provide her guidance on how to use it. She mentioned being very satisfied with the checkout selection, thanks to the friendly service employee.

\section{Habitual SCO user (Site C)}

A 26-year old woman was shopping alone and carried four small purchases in her hands. After entering the checkout area, she determinedly rushed towards SCOs, all of which were free at the moment. After checking out, she accepted the request for a short interview despite being in a bit of a hurry. It was her lunch break and she did not want to waste much time.

She was working at the upper floor of the same building, comes to this store every day, and tends to use SCOs. Consequently, the decision to use SCO was perfunctory and already made before entering the store. Thus, she did not observe the checkout area at all (1 out of 7). The reason for selecting SCO was that she finds it fast to use (relative importance of $80 \%$ ) and 
usually there is no waiting line (20\%). Only if the self-checkouts are closed, a situation that may occur in the early morning, she would choose traditional checkout. She intends to continue using self-checkouts also in the future.

\section{Situational user: traditional checkout (Site A)}

A 51-year old man was moving back and forth at the checkout area, contemplating on whether to use SCO or go to traditional checkout. Finally, he made up his mind and started to queue for a traditional checkout. While standing in the slowly proceeding waiting line, he kept glancing the half-empty SCO area as well as the waiting lines to other traditional checkouts. This slight hesitation was noticeable.

The man was shopping with his wife and daughter who had already left the store. He had a shopping basket filled with 11 items and used a credit card to pay them. Even though his companions were waiting for him outside the store, he accepted the request for an interview. The man explained that before choosing the checkout, he observed the whole checkout area (7 out of 7). After some contemplation, he chose a traditional checkout because the service employee seemed very professional. However, he was not fully satisfied with his decision because the waiting time was relatively long. In the future, he would possibly use SCO if the waiting line is significantly shorter compared to traditional checkouts. Previously he had used SCOs in Ikea and some other grocery stores.

\section{Situational user: SCO (Site A)}

Holding two items in his hands, this 63-year old man selected an empty SCO and executed the transaction effortlessly. It was not his first time to use SCO: he comes to this grocery store every day and has already adopted the system. However, he does not always choose SCO. His decision was based on careful consideration and observations (7 out of 7 ) of the checkout area. He explained that if the traditional checkouts were free or he had many purchases, he might select the traditional checkout. Otherwise, he tends to choose SCO because of the anonymity and privacy it provides.

While he was satisfied with his checkout selection, he also mentioned that SCOs have their disadvantages. For instance, he finds that the machines are not ergonomic to use, the plastic bags are not opened beforehand, and the annoying reminder of the bonus card is repeated every time. Despite the shortcomings, he intends to continue SCO usage in the future.

\section{Drifting user (Site C)}

A British couple, a man and a woman both in their late twenties, checked out through traditional till. When asked about their choice, they were surprised as they had not really thought about it. They explained that they do not have any particular habit regarding checking out from a store; rather, the decision is usually random or instantaneous. While they reported having observed the checkout area a bit, they did not reflect on which checkout to choose but merely drifted to the closest one available. Since there was no queue at this checkout, the choice felt natural to them. However, when prompted on other possible factors that may influence their decisions, they mentioned that they find traditional checkout as effortless. Nevertheless, they have used SCOs before and intend to use them again, especially if they are not carrying many purchases and the traditional checkouts have long queues. 
Copyright: () 2021 authors. This is an open-access article distributed under the terms of the Creative Commons Attribution-NonCommercial 3.0 Australia License, which permits noncommercial use, distribution, and reproduction in any medium, provided the original author and AJIS are credited.

doi: https://doi.org/10.3127/ajis.v25i0.2671

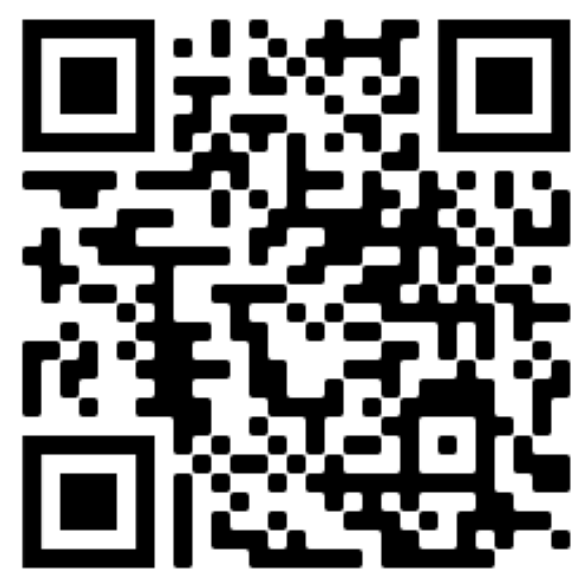

